\title{
USE OF TABULATED THERMOCHEMICAL DATA FOR PURE COMPOUNDS
}

\author{
Nathan S. Jacobson \\ NASA John H. Glenn Research Center \\ Cleveland, $\mathrm{OH} 44135$
}

\begin{abstract}
Thermodynamic data for inorganic compounds is found in a variety of tabulations and computer databases. An extensive listing of sources of inorganic thermodynamic data is provided. The three major tabulations are the JANAF tables (1). Thermodynamic Properties of Individual Substances (2), and the tabulation by Barin (3). The notation and choice of standard states is different in each of these tabulations, so combining data from the different tabulations is often a problem. By understanding the choice of standard states, it is possible to develop simple equations for conversion of the data from one form to another.
\end{abstract}

Key Words: Computational Chemistry, Physical Chemistry, Tabulations, Thermodynamics, 


\section{Introduction}

Thermodynamic data for the elements and compounds are tabulated in a variety of handbooks and electronic databases. Appendix I lists the tabulations (1-19) currently in common use, along with the format (tabular, analytic functions, electronic), and the quantities tabulated. These tabulations represent many years of intensive work-both in the measurements and the gathering and assessment of the data in these tables. The focus here will be on the first three tabulations. Most of the data in the remaining tabulations have been incorporated into these. Some of the data have been critically assessed for reliability, other data have not. Generally the JANAF (1) and TPIS (2) compendia are considered to have the highest degree of reliability.

The goal with each of these databases is to reliably and accurately calculate free energy changes in a reacting system and determine the resultant product assemblage. This is done either by (i) determining the free energy change of a single balanced reaction with reactants and products explicitly specified or (ii) with a free energy minimization computer code (20) where only the reactants are specified and the products and product amounts are determined by the code. To this end, each database presents the same basic thermodynamic information. However the form and choice of reference states differs for each database. Even the notation may differ from table to table. Appendix II lists the notation used in the first three tabulations. This report follows the JANAF tables (1) and the notation recommended in an IUPAC report (21) as closely as possible.

Bale and Eriksson (22) have reviewed eight integrated thermodynamic databases (ITDs). These are commercially available databases and codes for metallurgical thermochemistry. They discuss both the databases and the features of the accompanying codes. In addition a wealth of information on computer thermochemical codes is available on the directory of web sites in 
Inorganic Chemical Thermodynamics--http://www.crct.polymtl.ca/FACT/websites.htm, maintained by Ecole Polytechnique of Montreal, Canada.

The emphasis here is on stand-alone databases for pure substances and their enthalpy, entropy, and Gibbs free energy at constant pressure-the quantities most often used in high temperature inorganic thermochemistry. The goal of this report is to describe the form of the data in each database and show how to easily convert the data from one form to another. The current trend in electronic databases is to store thermodynamic information as the Gibbs Energy Function, referenced to the standard state at $298.15 \mathrm{~K}$. This function and standard state are not generally treated in thermodynamics textbooks and therefore will be discussed in detail here.

\section{Tabulated Enthalpies}

Heat capacity, $C_{p}^{\prime \prime}(T)$, is often expressed as the following polynomial function.

$C^{\prime \prime \prime}(T)=a+b T+c T^{-2}$

Here $T$ is the temperature in degrees Kelvin. A fourth term $d T^{2}$ is sometimes included (23).

Enthalpy, $H^{\prime \prime}(T)$, is defined as:

$H^{\prime \prime}(T)-H^{\prime \prime}(298)=\int_{298}^{r} C_{p}^{\prime \prime}(T) d T$

Integrating equation (1), we obtain: 
$H^{\prime \prime}(T)-I^{\prime \prime}(298)=a T+\frac{b}{2} T^{2}-\frac{c}{T}-a(298)-\frac{b}{2}(298)^{2}-\frac{c}{298}$

The enthalpy is only meaningful as a difference. $H^{\prime \prime}(T)$ alone is only meaningful if a value for $H^{\prime \prime}(298)$ is specified. In the JANAF tables (1) enthalpies are always expressed as the difference in equation (2). Thus the JANAF tables (1) list $H^{\prime \prime}(T)-H^{\prime \prime}\left(T_{r}\right)$ for every element and compound, with $T_{r}$ equal to $298.15 \mathrm{~K}$. This means that $H^{\prime \prime}(T)-H^{\prime \prime}\left(T_{r}\right)$ is zero at $298.15 \mathrm{~K}$, negative when $T_{r}<298.15 \mathrm{~K}$, and positive when $T_{r}>298.15 \mathrm{~K}$. Table $\mathrm{I}$ gives an example of the JANAF (1) listing of $H^{\prime \prime}(T)-H^{\prime \prime}\left(T_{r}\right)$ for Al(cr): 


\begin{tabular}{|l|l|}
\hline $\mathrm{T}(\mathrm{K})$ & $H^{\prime \prime}(T)-H^{\prime \prime}\left(T_{r}\right)$ \\
\hline 0 & -4.539 \\
\hline 100 & -4.056 \\
\hline 200 & -2.254 \\
\hline 250 & -1.140 \\
\hline 298.15 & 0. \\
\hline 300 & 0.045 \\
\hline 350 & 1.280 \\
\hline 400 & 2.553 \\
\hline 450 & 3.856 \\
\hline 500 & 5.186 \\
\hline 900 & 7.921 \\
\hline
\end{tabular}

Table I. Selected data for $H^{\prime \prime}(T)-H^{\prime \prime}\left(T_{r}\right)$ for Al(cr) from the JANAF (1) tables. 
The JANAF tables (1) also list the heat of formation $\Delta_{,} H^{\prime \prime}(T)$ for each substance. For the elements in their conventional standard states, this is zero. However for the compounds, it is defined as follows. Following the notation of Barin (2), consider the formation of a compound B from the elements $E_{i}$ :

$v_{1} E_{1}+v_{2} E_{2}+\ldots=B$

First consider the determination of $\Delta_{f} H^{\prime \prime}(298)$ :

$\Delta_{,} H^{\prime \prime}(298, B)=H^{\prime \prime}(298, B)-\sum_{i} v_{i} H^{o}\left(298, E_{i}\right)$

Next consider the determination of $\Delta_{f} H^{\prime \prime}(T)$ :

$\Delta_{,} H^{\prime \prime}(T, B)=H^{\prime \prime}(T, B)-\sum_{i} v_{i} H^{\prime \prime}\left(T, E_{i}\right)$

Since the JANAF tables only present enthalpy data as the difference $H^{\circ}(T)-H^{\circ}(298)$, equation (5) can be subtracted from equation (6) to give:

$\Delta_{,} H^{\prime \prime}(T, B)=\Delta_{f} H^{\prime \prime}(298, B)+\left[H^{\prime \prime}(T, B)-H^{\prime \prime}(298, B)\right]-\sum_{i} v_{i}\left[H^{\prime \prime}\left(T, E_{i}\right)-H^{o}\left(298, E_{i}\right)\right]$ (7)

Equation (7) is thus used to determine the enthalpy of formation of $B$ at a temperature $T$. The TPIS compendium lists $\Delta_{f} H^{\prime \prime}(0)$ and $\Delta_{f} H^{\prime \prime}(298)$ as well as $H^{\prime \prime}(T)-H^{\prime \prime}(0)$. The enthalpy 
of formation at any temperature $\Delta, H^{\prime \prime}(T)$ can be calculated in manner analogous to that described above.

$\Delta, H^{\prime \prime}(T, B)=\Delta_{,} H^{\prime \prime}(0, B)+\left[H^{\prime \prime}(T, B)-H^{\prime \prime}(0, B)\right]-\sum_{i} v_{i}\left[H^{\circ}\left(T, E_{i}\right)-H^{o}\left(0, E_{i}\right)\right]$

Barin (3) also lists $H^{\prime \prime}(T)-H^{\prime \prime}(298)$, which is the same as the JANAF (1) $H^{o}(T)-H^{o}\left(T_{r}\right)$. In addition, Barin (3) lists the quantity $H^{\prime \prime}(T)$. In order to do this he uses the standard element reference state (SER), taking $H^{\prime \prime}(298)$ as zero for the elements in their most stable aggregation state at $298.15 \mathrm{~K}$. The use of the standard element reference state avoid anomalies encountered when the reference state is taken at the temperature of interest (5). As will be discussed, the major computerized databases use data with this reference state. First consider equation (5). The summation term is zero for the elements at $298.15 \mathrm{~K}$, so:

$\Delta, H^{\prime \prime}(298, B)=H^{\prime \prime}(298, B)$

Adding $H^{\prime \prime}(T, B)-H^{\prime \prime}(298, B)$ to both sides leads to (24):

$H^{\prime \prime}(T, B)=\Delta, H^{\prime \prime}(298, B)+\left(H^{\prime \prime}(T, B)-H^{\prime \prime}(298, B)\right)$

Equation (9) thus indicates how to convert from the JANAF data to the Barin $H^{\circ}(T)$. 


\section{Tabulated Entropies}

Tabulations of entropies are more clear than those for enthalpies since there is an absolute value for entropy. At zero degrees Kelvin, the entropy equals to zero. Entropy can be determined from:

$d S=\frac{C_{p}^{\prime \prime} d T}{T}$

Now this can be integrated to:

$S^{\prime \prime}(T)=S^{\prime \prime}(298)+a \ln T+b T-\frac{c}{3} T^{-3}$

$S^{\prime \prime}(298)$ can be determined from low temperature measurements:

$S^{\prime \prime \prime}(298)-S^{\prime \prime}(0)=S^{\prime \prime}(298)=\int_{0}^{298} \frac{C_{p}^{\prime \prime}(T) d T}{T}$

The major compendia-JANAF, TPIS, and Barin—list entropy exactly the same way. 


\section{Tabulated Free Energies}

III.A. JANAF $\triangle, G^{\prime \prime}(T), F E F(298)$

The JANAF tables (1) present free energy functions referenced to $298.15 \mathrm{~K}$ and the Gibbs free energy of formation $\Delta, G^{\prime \prime}(T)$. According to convention, the free energy of formation of the elements in their pure form, at the temperature of interest, is taken as zero. Thus $\Delta, G^{\circ}(T)$ is zero for all pure elements. However it is not zero for compounds. The free energy function referenced to $298.15 \mathrm{~K}$ is extremely useful. It is defined as:

$\operatorname{FEF}(298)=\frac{\left[G^{\prime \prime}(T)-H^{\prime \prime}(298)\right]}{T}$

Consider reaction (4). The Gibbs free energy of formation for compound $B$ can be calculated from the free energy function as follows:

$$
\frac{\Delta, G(T, B)}{T}=\operatorname{FEF}(298, B)-\sum_{i} v_{i}\left[F E F\left(298, E_{i}\right)\right]+\frac{\Delta_{f} H^{\circ}(298, B)}{T}
$$

The ease of interpolation with the free energy function made it the favored choice for thermodynamic calculations until recently. However today, with near universal use of computers, polynomial expressions for free energies of formation are more widely used.

Table IIla and IIIb illustrates the entries for these quantities from the JANAF tables (1). 


\begin{tabular}{|l|l|l|l|l|l|}
\hline T/K & $S^{\prime \prime}(T)$ & $-F E F(298)$ & $H^{\prime \prime}(T)-H^{\prime \prime}(298)$ & $\Delta_{f} H^{\prime \prime}(T)$ & $\Delta, G^{\prime \prime}(T)$ \\
\hline 0 & 0 & & -3.218 & 0 & 0 \\
\hline 100 & 3.833 & 33.351 & -2.952 & 0 & 0 \\
\hline 298.15 & 18.820 & 18.820 & 0 & 0 & 0 \\
\hline 500 & 30.110 & 21.237 & 4.436 & 0 & 0 \\
\hline 1000 & 47.329 & 30.387 & 16.942 & 0 & 0 \\
\hline 1500 & 58.411 & 37.982 & 30.644 & 0 & 0 \\
\hline
\end{tabular}

Table IIla. Selected JANAF table (1) entries for Si(s)

\begin{tabular}{|l|l|l|l|l|l|}
\hline $\mathrm{T} / \mathrm{K}$ & $S^{\prime \prime}(T)$ & $\frac{-\left[G^{\prime \prime}(T)-H^{\prime \prime}(298)\right]}{T}$ & $H^{\circ}(T)-H^{\circ}(298)$ & $\Delta_{f} H^{\prime \prime}(T)$ & $\Delta_{f} G^{\circ}(T)$ \\
\hline 0 & 0 & & -7.550 & 445.668 & 445.668 \\
\hline 100 & 140.886 & 188.980 & -4.809 & 448.142 & 434.437 \\
\hline 298.15 & 167.980 & 167.980 & 0 & 450.000 & 405.528 \\
\hline 500 & 179.204 & 170.456 & 4.374 & 449.938 & 375.391 \\
\hline 1000 & 193.816 & 178.911 & 14.905 & 447.962 & 301.476 \\
\hline 1500 & 202.360 & 185.396 & 25.447 & 444.803 & 228.879 \\
\hline
\end{tabular}

Table Illb. Selected JANAF table (1) entries for Si(g) 
III.B. TPIS $F E F(0)$

The TPIS compendium (2) lists only the free energy function referenced to $0 \mathrm{~K}$. This is defined as:

$F E F(0)=\frac{\left[G^{\prime \prime}(T)-H^{\prime \prime}(0)\right]}{T}$

This free energy function for gaseous molecules is readily calculated from spectroscopic data (25). In analogy with equation (14) above, the free energy of formation of compound $B$ in reaction (4) can be calculated as:

$$
\frac{\Delta, G^{\prime \prime}(T, B)}{T}=F E F(0, B)-\sum_{i} v_{i}\left[F E F\left(0, E_{i}\right)\right]+\frac{\Delta_{i} H^{\prime \prime}(0, B)}{T}
$$

The problem is that for this free energy of formation-and any free energy change calculation-$\Delta, H^{\prime \prime}(0)$ is needed and this not always available

The free energy function referenced to $0 \mathrm{~K}$ can be converted to the free energy function referenced to $298.15 \mathrm{~K}$, as follows:

$$
F E F(0)=\frac{-\left[G^{\prime \prime}-H^{\prime \prime}(298)\right]}{T}-\frac{\left[H^{\prime \prime}(298)-H^{\prime \prime}(0)\right]}{T}
$$

The second term is calculated from the low temperature heat capacities. As pointed out by Lewis and Randall (25), reasonable estimates can be made for this which introduce little error. The free 
energy function referenced to $298.15 \mathrm{~K}$ is given in the JANAF tables (1) and the compendium of Barin (3)

III.C. Barin $F E F(298), \Delta, G^{\prime \prime}(T), G^{\prime \prime}(T)$

The tables of Barin (3) give the same $F E F(298)$ and $\Delta_{f} G^{\circ}(T)$, but they also include $G^{o}(T)$, which is the Gibbs energy (26). It should be noted that Barin (3) refers to the free energy function referenced to $298.15 \mathrm{~K}$ as the "Gibbs energy function" or the "free enthalpy function". This somewhat confusing nomenclature and the "free energy function" is more commonly used. Selected entries from Barin for Si(s) and Si(g) are given in Tables IVa and IVb. 


\begin{tabular}{|l|l|l|l|l|l|}
\hline T/K & $H^{\prime \prime}(T)$ & $H^{\prime \prime}(T)-H^{\prime \prime}(298)$ & $\Delta_{f} H^{\prime \prime}(T)$ & $G^{\prime \prime}(T)$ & $\Delta_{f} G^{\prime \prime}(T)$ \\
\hline 298.15 & 0 & 0 & 0 & -5.611 & 0 \\
\hline 500 & 4.438 & 4.438 & 0 & -10.619 & 0 \\
\hline 1000 & 16.943 & 16.943 & 0 & -30.390 & 0 \\
\hline 1500 & 30.648 & 30.648 & 0 & -56.979 & 0 \\
\hline
\end{tabular}

Table IVa. Selected values from Barin (3) for Si(s). S and FEF(298) are the same as those in the JANAF tables (1).

\begin{tabular}{|l|l|l|l|l|l|}
\hline $\mathrm{T} / \mathrm{K}$ & $H^{\prime \prime}(T)$ & $H^{\prime \prime}(T)-H^{\prime \prime}(298)$ & $\Delta_{f} H^{\prime \prime}(T)$ & $G^{\prime \prime}(T)$ & $\Delta_{f} G^{\prime \prime}(T)$ \\
\hline 298.15 & 450.000 & 0 & 450.000 & 399.917 & 405.528 \\
\hline 500 & 454.373 & 4.373 & 449.935 & 364.773 & 375.392 \\
\hline 1000 & 464.903 & 14.903 & 447.960 & 271.090 & 301.480 \\
\hline 1500 & 475.447 & 25.447 & 444.799 & 171.908 & 228.888 \\
\hline
\end{tabular}

Table IVb. Selected values from Barin (3) for Si(g). S and FEF(298) are the same as those in the JANAF tables (1). 
Again, consider reaction (4). The free energy of formation of compound B can be calculated from the Gibbs energy functions as follows:

$$
\Delta_{i} G^{\prime \prime}(T, B)=G^{\prime \prime}(T, B)-\sum_{i} v_{i} G^{\prime \prime}\left(T, E_{i}\right)
$$

Thus if the free energy of formation of a compound is known from the JANAF tables (1) and the Gibbs energy functions for its constituent elements are known, the compound's Gibbs energy function is:

$G^{\prime \prime}(T, B)=\Delta, G^{\prime \prime}(T, B)+\sum_{i} v_{i} G^{\prime \prime}\left(T, E_{i}\right)$

Using the JANAF table (1) data only, we can convert to Gibbs energy functions via the following:

$G^{\prime \prime}(T)=H^{\prime \prime}(T)-T S^{\prime \prime}(T)=\left[\Delta, H^{\prime \prime}(298)+\left(H^{\prime \prime}(T)-H^{\prime \prime}(298)\right)\right]-T S^{\prime \prime}(T)$

Also note that $G^{\prime \prime}(T)$ is the first term in the free energy function referenced to $298.15 \mathrm{~K}$. Thus for pure elements, where $H^{\prime \prime}(298)$ is equal to zero:

$G^{\prime \prime}(T)=-F E F(298) * T$

For compounds where $H^{\prime \prime}(298)$ does not equal zero, we can use $F E F(298)$ to calculate $G^{\prime \prime}(T)$ as follows:

$G^{\prime \prime}(T)=\left[\Delta, H^{\prime \prime}(298)+\left(H^{\prime \prime}(T)-H^{\prime \prime}(298)\right]-T^{*}[F E F(298)]\right.$ 
By definition the Gibbs energy is referenced to the elements in their most stable aggregation at 298.15 K. Dinsdale (5) has taken data from a range of sources and converted it to the Gibbs energy functions. These data is most commonly used in computer databases (eg SGTE database) for thermochemical calculations. It is often written as:

G - HSER or $\mathrm{G}-\mathrm{H}_{298}$

Here HSER or $\mathrm{H}_{298}$ is the weighted average of the elements in the particular compound (27), which is zero. Thus the HSER in the above quantities is always zero and simply a mnemonic to specify the Gibbs energy referenced to $298.15 \mathrm{~K}$. Typically $G-H S E R$ is presented in the following functional form:

$G-H S E R=a+b T+c T \ln (T)+\sum_{n} d_{n} T^{n}$

Generally the power terms are:

$G-H S E R=a+b T+c T \ln (T)+d_{1} T^{2}+d_{2} T^{3}+d_{3} T^{-1}$

This expression can be easily differentiated to obtain the entropy:

$$
S=-\left(\frac{\partial(G-H S E R)}{\partial T}\right)_{p}
$$


the enthalpy:

$$
H=\left(\frac{\partial[(G-H S E R) / T]}{\partial(1 / T)}\right)_{l}
$$

and the heat capacity:

$C^{\prime}{ }_{\prime \prime}=-T\left(\frac{\partial^{2}(G-H S E R)}{\partial T^{2}}\right)_{,}$

\section{Summary and Conclusions}

There are numerous sources of thermochemical data for inorganic compounds at high temperatures. However the data in these compendia are often in very different forms. In this report we survey the main compendia and catalog the forms of the data presented. Equations are provided for easy conversion between the different data forms.

The most recent databases contain thermodynamic data in the form of the Gibbs energy function.

This is referenced to $298.15 \mathrm{~K}$. This function and its relation to Gibbs energies of formation and to free energy functions are discussed. 
Appendix I. Tabulations of Thermochemical Data

\begin{tabular}{|c|c|c|c|}
\hline Author, Title, Date & Format & Quantities & Ref \\
\hline $\begin{array}{l}\text { Chase, et. al., JANAF } \\
\text { Thermochemical Tables (1998) }\end{array}$ & $\begin{array}{l}\text { Tabular, } \\
\text { Electronic }\end{array}$ & $\begin{array}{l}C_{p}^{\prime \prime}(T), S^{\prime \prime}(T), F E F(298), H^{\prime \prime}(T)-H^{o}\left(T_{r}\right), \\
\Delta_{f} H^{\prime \prime}(T), \Delta_{f} G^{\prime \prime}(T), \log K_{f}, \Delta_{l r} H\end{array}$ & 1 \\
\hline $\begin{array}{l}\text { Gurvich, et. al., Thermochemical } \\
\text { Properties of Indivual Substances } \\
\text { (1989) }\end{array}$ & $\begin{array}{l}\text { Tabular, } \\
\text { Electronic }\end{array}$ & $\begin{array}{l}C_{p}^{\prime \prime}(T), F E F(0), H^{\prime \prime}(T)-H^{\prime \prime}(0), S^{\prime \prime}(T), \\
\log K_{f}, \Delta_{,} H^{\prime \prime}(0), \Delta_{,} H^{\prime}(298), \Delta_{\prime r} H^{\prime \prime}\end{array}$ & 2 \\
\hline $\begin{array}{l}\text { Barin, Thermochemical Data of } \\
\text { the Indivual Substances (1989) }\end{array}$ & Tabular & $\begin{array}{l}C_{p}^{\prime \prime}(T), S^{o}(T), F E F(298), H^{o}(T), \\
H^{\prime \prime}(T)-H^{\prime \prime}(298), G^{\prime \prime}(T), \Delta_{f} H^{o}(T) \\
\Delta_{f} G^{\prime \prime}(T), \log K_{f}, \Delta_{l r} H\end{array}$ & 3 \\
\hline $\begin{array}{l}\text { Pankratz, Thermodynamic } \\
\text { Properties of Elements and } \\
\text { Oxides (1982) } \\
\text { Pankratz, Thermodynamic } \\
\text { Properties of Halides (1984) } \\
\text { Pankratz, Mah, and Watson, } \\
\text { Thermodynamic Properties of } \\
\text { Sulfides (1987) } \\
\text { Pankratz, Thermodynamic } \\
\text { Properties of Carbides, Nitrides, } \\
\text { and other Selected Substances } \\
\text { (1994) } \\
\text { Pankratz, Stuve, and Gokcen, }\end{array}$ & $\begin{array}{l}\text { Tabular, } \\
\text { Functional }\end{array}$ & $\begin{array}{l}C_{p}^{\prime \prime}, S^{\prime \prime}(T), F E F(298), H^{\prime \prime}(T)-H^{\prime \prime}(298) \\
\Delta_{,} H^{\prime \prime}, \Delta_{f} G^{\prime \prime}(T), \log K_{f}, \Delta_{r} H \\
\\
C_{p}^{T}, S^{\prime \prime}(T), H^{\prime \prime}(T)-H^{\prime \prime}(298) \\
\Delta_{f} H^{\prime \prime}(T), \Delta_{f} G^{\prime \prime}(T)\end{array}$ & 4 \\
\hline
\end{tabular}




\begin{tabular}{|c|c|c|c|}
\hline $\begin{array}{l}\text { Thermodynamic Data for Mineral } \\
\text { Technology (1984) }\end{array}$ & & & \\
\hline $\begin{array}{l}\text { Dinsdale, SGTE Data for Pure } \\
\text { Elements (1991) }\end{array}$ & Functional & $G-H S E R$ & 5 \\
\hline SGTE Database & Electronic & $\begin{array}{l}G-H S E R \text { for most compounds } \\
C_{p}^{\prime \prime}, \Delta_{f} H^{\prime \prime}(298) \text { for some compounds }\end{array}$ & 6 \\
\hline Database for $\mathrm{HSC}$ & $\begin{array}{l}\text { Electronic } \\
\text { Functional }\end{array}$ & $\Delta_{f} H^{\prime \prime}(298), S^{\prime \prime}(298), C_{p}^{\prime \prime}(T)$ & 7 \\
\hline $\begin{array}{l}\text { Cox, et al., CODATA Key Values } \\
\text { for Thermodynamics (1989) }\end{array}$ & Tabular & $C_{p}^{\prime \prime}(T), F E F(0), H^{o}(T)-H^{\prime \prime}(0)$ & 8 \\
\hline $\begin{array}{l}\text { Hultgren, et. al., Selected Values } \\
\text { of the Thermodynamic Properties } \\
\text { of the Elements (1973) }\end{array}$ & Tabular & $\begin{array}{l}C_{p}^{\prime \prime}, H^{\prime \prime}(T)-H^{\prime \prime}(298), S^{\prime \prime}(T)-S(298), \\
F E F(298), \Delta_{\text {vap }} G^{\prime \prime}, \Delta_{\text {vap }} H^{o}, \Delta_{\text {tr }} H, \log P(\text { vapor })\end{array}$ & 9 \\
\hline $\begin{array}{l}\text { Robie and Hemingway, } \\
\text { Thermodyanamic Properties of } \\
\text { Minerals and Related Substances } \\
\text { at } 298.15 \mathrm{~K} \text { and } 1 \text { Bar Pressure } \\
\text { and Higher Temperatures }\end{array}$ & Tabular & $\begin{array}{l}S^{o}(298), \Delta_{f} H^{o}(298), \Delta_{f} G^{o}(298) \text { for many } \\
\text { minerals } \\
C_{p}^{o}(T), S_{T}^{o}(T), H^{o}(T)-H^{o}(298), F E F(298), \\
\Delta_{f} H^{\prime \prime}(T), \Delta_{f} G^{o}(T), \log K_{f}, \Delta_{t r} H(T) \text { for } \\
\text { selected minerals }\end{array}$ & 10 \\
\hline $\begin{array}{l}\text { Kubachewski, } \\
\text { The Thermodynamic Properties of } \\
\text { Double Oxides }\end{array}$ & Functional & $\Delta, G$ & 11 \\
\hline $\begin{array}{l}\text { Kubachewski, Alcock, and } \\
\text { Spencer, Materials } \\
\text { Thermochemistry }\end{array}$ & $\begin{array}{l}\text { Tabular, } \\
\text { Functional }\end{array}$ & $C_{p}^{\prime \prime}(T), S^{\prime \prime}(298), \Delta_{f} H^{\prime \prime}(298), \Delta_{t r} H$ & 12 \\
\hline
\end{tabular}




\begin{tabular}{|c|c|c|c|}
\hline $\begin{array}{l}\text { Elliot and Glieser, } \\
\text { Thermochemistry for Steel Making }\end{array}$ & Tabular & $\begin{array}{l}C_{p}^{\prime \prime}(T), S^{\prime \prime}(T), F E F(298), H^{\prime \prime}(T)-H^{\prime \prime}\left(T_{r}\right) \\
\Delta_{f} H^{\prime \prime}(T), \Delta_{,} G^{\prime \prime}(T), \log K_{f}, \Delta_{r} H\end{array}$ & 13 \\
\hline $\begin{array}{l}\text { Mills, Thermodynamic Data for } \\
\text { Inorganic Sulfides, Selenides, and } \\
\text { Tellurides (1974) }\end{array}$ & Tabular & $\begin{array}{l}C_{p}^{\prime \prime}(T), S^{\prime \prime}(T), F E F(298) \\
H^{\prime \prime}(T)-H^{\prime \prime}(298), \Delta_{f} H^{\prime \prime}(T) \\
\Delta_{f} G^{\prime \prime}(T), \log K_{p}\end{array}$ & 14 \\
\hline $\begin{array}{l}\text { Chang and Ahmad, } \\
\text { Thermodynamic Data on Metal } \\
\text { Carbonates and Related Oxides } \\
\text { (1982) }\end{array}$ & Tabular & $\begin{array}{l}C_{p}^{\prime \prime}(T), S^{\prime \prime}(T), F E F(298), H^{\prime \prime}(T)-H^{\prime \prime}(298), \\
\Delta_{,} G^{\prime \prime}(T) \text { for the carbonate from the metal oxide } \\
\text { and } \mathrm{CO}_{2}\end{array}$ & 15 \\
\hline $\begin{array}{l}\text { Schick, Thermodynamics of } \\
\text { Certain Refractory Compounds } \\
\text { (1966) }\end{array}$ & Tabular & $\begin{array}{l}C_{p}^{\prime \prime}(T), S^{\prime \prime}(T), F E F(298), H^{\prime \prime}(T)-H^{\prime \prime}(298), \\
\Delta_{f} H^{\prime \prime}(T), \Delta_{f} G^{\prime \prime}(T), \log K_{p}\end{array}$ & 16 \\
\hline $\begin{array}{l}\text { Rossini, et. al., Selected Values of } \\
\text { Chemical Thermodynamic } \\
\text { Properties (1961) }\end{array}$ & Tabular & $\begin{array}{l}C_{p}^{\prime \prime}(298), S^{\prime}(298), \Delta_{f} H^{\prime \prime}(0) \\
\Delta_{f} H^{\prime \prime}(298), \Delta_{f} G^{\prime \prime}(298)\end{array}$ & 17 \\
\hline $\begin{array}{l}\text { Stull and Sinke, Thermodynamic } \\
\text { Properties of the Elements (1956) }\end{array}$ & Tabular & $\begin{array}{l}C_{p}^{\prime \prime}(T), H^{\prime \prime}(T)-H^{\prime \prime}(298), S^{\prime \prime}(T) \\
F E F(298), \Delta_{f} H^{\prime \prime}(T), \Delta_{f} G^{\prime}(T)\end{array}$ & 18 \\
\hline $\begin{array}{l}\text { Wagman, et. al., Selected Values } \\
\text { of Chemical Thermodynamic } \\
\text { Properties (1965) }\end{array}$ & Tabular & $\begin{array}{l}C_{p}^{\prime \prime}(T), S^{\prime \prime}(298), \Delta_{f} H^{\prime \prime}(0), \Delta_{f} H^{\prime \prime}(298), \\
\Delta_{f} G^{\prime \prime}(298), H^{\prime \prime}(298)-H^{\prime \prime}(0)\end{array}$ & 19 \\
\hline
\end{tabular}


Appendix II. Notation in the JANAF (1), TPIS(2), Barin (3), and this report.

\begin{tabular}{|c|c|c|c|c|}
\hline JANAF (1) & TPIS (2) & Barin (3) & This Report & Meaning \\
\hline$T$ & $T$ & $T$ & $T$ & Absolute temperature, degrees Kelvin \\
\hline$(", ")$ & $C_{p}^{\prime \prime \prime}(T)$ & $C_{p}$ & $C_{p}^{u}(T)$ & $\begin{array}{l}\text { Heat Capacity at constant } \\
\text { Pressure }\end{array}$ \\
\hline$s^{\prime \prime \prime}$ & $S^{\prime \prime}(T)$ & $S$ & $S^{\prime \prime}(T)$ & $\begin{array}{l}\text { Absolute entropy of a given substance, } \\
\text { equal to zero at } 0 \mathrm{~K}\end{array}$ \\
\hline \multirow[t]{4}{*}{$\left(r^{\prime \prime}-H^{\prime \prime}\left(T_{r}\right)\right] / T$} & & $(G-H 298)$ & $F E F(298)$ & $\begin{array}{l}\text { Free energy function referenced } \\
\text { to } 298.15 \mathrm{~K}\end{array}$ \\
\hline & $\Phi^{\prime \prime}(T)$ & & $F E F(0)$ & $\begin{array}{l}\text { Free energy function } \\
\text { Referenced to } \mathrm{OK}\end{array}$ \\
\hline & $H^{\prime \prime}(T)-H^{\prime \prime}(0)$ & & & $\begin{array}{l}\text { Enthalpy difference between enthalpy at } \\
\text { temperature } \mathrm{T} \text { and } \mathrm{OK}\end{array}$ \\
\hline & & $H$ & $H^{\prime \prime}(T, B)$ & $\begin{array}{l}\text { Enthalpy for compound B-B not always } \\
\text { included if it is clear from the context }\end{array}$ \\
\hline$H^{\prime \prime}-H^{\prime \prime}\left(T_{r}\right)$ & & $H-H 298$ & & $\begin{array}{l}\text { Enthalpy difference between } \\
\text { Enthalpy at temperature } \mathrm{T} \text { and } 298.15 \mathrm{~K}\end{array}$ \\
\hline \multirow[t]{2}{*}{$\Delta, H^{\prime \prime}$} & $\Delta, H^{\prime \prime}(T)$ & $\Delta H$ & $\Delta_{f} H^{\prime \prime}(T)$ & $\begin{array}{l}\text { Enthalpy of formation of a given } \\
\text { substance from the elements in their } \\
\text { conventional standard states at a } \\
\text { temperature } T\end{array}$ \\
\hline & & $G$ & $\begin{array}{l}G^{\prime \prime}(T), \\
G-H S E R\end{array}$ & Gibbs energy function \\
\hline$\Delta, G^{\prime \prime}$ & & $\Delta G_{j}$ & $\Delta_{f} G^{\prime \prime}(T)$ & $\begin{array}{l}\text { Gibbs energy of formation from the } \\
\text { elements in their conventional standard } \\
\text { states at a temperature } T\end{array}$ \\
\hline
\end{tabular}




\begin{tabular}{|c|c|c|c|c|}
\hline$K_{1}$ & $K^{\prime \prime}(T)$ & $K$, & $K_{i}$ & $\begin{array}{l}\text { Equilibrium constant for the formation of } \\
\text { the compounds from their elements in } \\
\text { conventional reference states }\end{array}$ \\
\hline Superscript $^{\circ}$ & Superscript $^{\circ}$ & & Superscript & $\begin{array}{l}\text { Conventional standard state-1 bar, } \\
\text { temperature of interest, most stable form } \\
\text { of the element at that temperature of } \\
\text { interest }\end{array}$ \\
\hline & & & SER & $\begin{array}{l}\text { Standard Element Reference State- } \\
1 \text { bar, } 298.15 \mathrm{~K}, \text { most stable form of the } \\
\text { element at } 298.15 \mathrm{~K}\end{array}$ \\
\hline$\Delta_{i r} I_{r}^{\prime \prime}$ & & $L$ & $\Delta_{r} H$ & Enthalpy of transformation \\
\hline
\end{tabular}




\section{Annotated Bibliography for Main Text and Appendices:}

1. The JANAF are perhaps the most widely used thermochemical tables. This data has been carefully assessed. A detailed description is given for the source of each data set. It is now in its fourth edition, although the second and third editions are still in common use:

1a. Stull, D. R. and Prophet, H. JANAF Thermochemical Tables, $2^{\text {nd }}$ ed.; NSRDS-NBS 37, National Bureau of Standards: Washington, DC, 1971.

1b. Chase, M. W. Jr., Davies, C. A., Downey, J. R. Jr., Frurip, D. J., McDonald, R. A., and Syerud, A. N. JANAF Thermochemical Tables, $3^{\text {rd }}$ ed.; Journal of Physical and Chemical Reference Data, Volume 14, 1985, American Chemical Society and American Physical Society for National Bureau of Standards: New York, NY, 1986.

1b. Chase, M. W. Jr. NIST-JANAF Thermochemical Tables, $4^{\text {th }}$ ed.; Journal of Physical and Chemical Reference Data, Monograph No. 9, American Chemical Society and American Physical Society for National Bureau of Standards: New York, NY, 1998.

1c. Some of the JANAF tables and a good deal of useful information is available on the NIST Chemistry Web Page: http://webbook.nist.gov/chemistry/

2. The Russian tables "Thermodynamic Properties of Individual Substances" (TPIS) are also carefully assessed data. A detailed text describes the sources of the data and a level of accuracy is given to each substance. Listed below are three versions-the Russian version, the English translation of Volumes $1-3$, Volume 4 is expected out soon, and the electronic version. The 
electronic version has the option of selecting the format of the output: JANAF form, TPIS form, or functional form of $C^{\prime \prime \prime}, F E F(0), F E F(298), H^{\prime \prime}(T)-H^{\prime \prime}(0), H^{\prime \prime}(T)-H^{\prime \prime}(298)$, and $S^{\prime \prime}(T)$.

2.a. Glusko, V. P., Gurvich, L. V., Bergman, G. A., Veitz, I. V., Medvedev, V. A., Khachkuruzov, G. A., and Jungman, V. S. Thermodynamic Properties of Pure Substances, $3^{\text {rd }}$ ed., Volumes I-IV, Nauka Publishers: Moscow, 1982 (in Russian).

2.b.i. Gurvich, L. V., Veyts, I. V., and Alcock, C. B. Thermodynamic Properties of Indivual Substances, $4^{\text {th }}$ ed., Volumes I and II. Hemisphere Publishing Corporation: New York, 1989.

2.b.ii. Gurvich, L. V., Veyts, I. V., and Alcock, C. B. Thermodynamic Properties of Indivual Substances, $4^{\text {th }}$ ed., Volume III, Begell House: New York, 1989.

2.b.iii. Gurvich, L. V., Veyts, I. V., and Alcock, C. B. Thermodynamic Properties of Indivual Substances, $4^{\text {th }}$ ed., Volume IV, Begell House: New York, to be published 1999.

2.c. Gurvich, L. V., Iorish, V. S., Chekhovskoi, D. V., Yungman, V. S. IVTANTHERMO-A Thermodynamic Database and Software System for the Personal Computer, NIST Special Database 5, National Institutes of Standards and Technology: Gathersburg, MD, 1993.

3. The tables of Barin and Knacke do not appear to be as thoroughly assessed data. The tables are the only major tables to contain data in the form of the Gibbs energy function, as discussed in the text. The older version gives the heat capacity in both tabular and functional form, as opposed to the newer version, which only gives the heat capacity in tabular form.

3.a.i Barin, I. and Knacke, O. Thermochemical Properties of Inorganic Substances, SpringerVerlag: Berlin, 1973. 
3.a.ii. Barin, I., Knacke, O., and Kubachewski, O. Thermochemical Properties of Inorganic Substances, Springer-Verlag: Berlin, 1977

3b. Barin, I. Thermochemical Data of Pure Substances, Volumes 1 and 2, $\mathrm{VCH}$ : Wienheim, Germany, 1989.

4. This is a series of Bulletins from the former US Bureau of Mines.

4a. Pankratz, L. B. Thermodynamic Data of Elements and Oxides, Bulletin 672, US Department of the Interior, Bureau of Mines: Washington, D.C., 1982.

4b. Pankratz, L. B. Thermodynamic Properties of Halides, Bulletin 674, US Department of the Interior, Bureau of Mines, Washington, D.C., 1984.

4c. Pankratz, L. B., Mah, A. D., and Watson, S. W. Thermodynamic Properties of the Sulfides, Bulletin 388, US Department of the Interior, Bureau of Mines, Washington, D. C., 1987.

4d. Pankratz, L. B. Thermodynamic Properties of Carbides, Nitrides, and other Selected Substances, Parts 1 and 2, Bulletin 696, US Department of the Interior, Bureau of Mines: Washington, D. C., 1994

4e. Pankratz, L. B., Stuve, J. M., and Gokcen, N. A. Thermodynamic Data for Mineral Technology, Bulletin 677, US Department of the Interior, Bureau of Mines, Washington, D. C., 1984.

5. Dinsdale, A. T., Calphad 1991, 15, 317-425. 
6. Scientific Group Thermodynamic Europe Pure Substance Database, Home Page http://www.sgte.org/ (accessed June 1999).

7. The database for this computational thermochemical code for pure substances is quite extensive, although it has not been assessed. The manual contains numerous references to additional data sources.

Roine, A. Outokumpu HSC Chemistry ${ }^{\circledR}$ for Windows, version 3.0, Outokumpu Research Oy, Finland, 1997

8. Cox, J. D., Wagman, D. D., and Medvedev, V. A. CODATA Key Values for Thermodynamics, Hemisphere, New York, 1989.

9. Hultgren, R., Desai, P. D., Hawkins, D. T., Gleiser, M., Kelley, and Wagman, D. D. Selected Values of the Thermodynamic Properties of the Elements, American Society for Metals: Metals Park, $\mathrm{OH}, 1973$.

10. This deals primarily with mineral compositions. It is available on the worldwide web at http://www.science.ubc.ca/\%7Egeol323/thermo/robtable.htm However the web version lists only data at $298.15 \mathrm{~K}$.

Robie, R. A. and Hemingway, B. S. Thermodyanamic Properties of Minerals and Related Substances at $298.15 \mathrm{~K}$ and 1 Bar Pressure and Higher Temperatures, Bulletin U.S. Geological Survey Bulletin 1452, United States Government Printing Office: Washington, 1978.

11. Kubachewski, O. High Temperatures - High Pressures 1972, 4, 1-12. 
12. The textbook by Kubachewski, Alcock and Spencer is a classic, now in its sixth edition. It contains a wealth of information on experimental thermochemistry as well as extensive tables.

Kubachewski, O., Alcock, C. B., and Spencer, P. J. Materials Thermochemistry, $6^{\text {th }}$ ed., Pergamon Press: New York, 1993.

13. This two volume set contains thermochemical data relevant to steelmaking.

13a. Elliot, J. F. and Gleiser, M. Thermochemistry for Steelmaking, Volume 1, Addison-Wesley Publishing Company: Reading, MA, 1960.

13b. Elliot, J. F. and Gleiser, M. Thermochemistry for Steelmaking, Volume 2, Addison-Wesley Publishing Company, Reading, MA, 1960.

14. This extensive compendium contains assessed data on the sulfides, selenides, and tellurides.

Mills, K. C. Thermodynamic Data for Inorganic Sulphides, Selenides, and Tellurides, Plenum: New York, 1974

15. Chang, Y. A. and Ahmad, N. Thermodynamic Data on Metal Carbonates and Related Oxides, The Metallurgical Society of AIME: Warrendale, PA, 1982.

16. Schick, H. L. Thermodynamic Properties of Certain Refractory Compounds, Volumes I and II, Academic Press: New York, 1966.

17. This is one of the earlier compendia and has been widely referenced. It was a basis for the 
more recent works.

F. D. Rossini, D. D. Wagman, W. H. Evans, S. Levine, and I. Jaffe Selected Values of Chemical Thermodynamic Properties, Part I: Tables and Part 11: References, Circular 500, National Bureau of Standards: Washington, D. C., 1961.

18. This contains elemental data in convenient form and is often quoted. However much of the data have since been updated.

Stull, D. R. and Sinke, G. C., Thermodynamic Properties of the Elements, American Chemical Society: Washington, D. C., 1956

19. Wagman, D. D., Evans, W. H., Halow, I., Parker, V. B., Bailey, S. M., and Schumm, R. H. Selected Values of Chemical Thermodynamic Properties Part I. Tables for the First Twenty-Three Elements in the Standard Order of Arrangement, Technical Note 270-1, National Bureau of Standards: Washington, D. C., 1965.

20. Eriksson, G. and Hack, K. Met. Trans. 1990, 21B, 1013.

21. "A Report of IUPAC Commission I.2 on Thermodynamics: Notation for States and Processes, Significance of the Word "Standard" in Chemical Thermodynamics, and Remarks on Commonly Tabulated Forms of Thermodynamic Functions," M-1448, J. Chem. Thermodynamics 1982, 14, 805

22. Bale, C. W. and Eriksson, G. Canadian Metall. Quart. 1990, 29, 105.

23. Gokcen, N. A. and Reddy, R. G. Thermodynamics, $2^{\text {nd }}$ ed., Plenum Press: New York, 1996. 
24. Turkdogan, E. T. Physical Chemistry of High Temperature Technology, Academic Press: New York, 1980.

25. Lewis, G. N. and Randall, M. Revised by Pitzer, K. S. and Brewer, L., Thermodynamics, McGraw Hill: New York, 1961.

26. Barin, I. and Knacke, O. Met. Trans. 1974, 5, 1769.

27. Hack, K., The SGTE Casebook Thermodynamics at Work, Institute of Materials: London, 1996. 